\title{
HOLISTIC QUALIFICATION IN MANUFACTURING METROLOGY BY ENHANCING KNOWLEDGE EXCHANGE AMONG DIFFERENT USER GROUPS
}

\author{
Albert Weckenmann, Teresa Werner \\ University Erlangen-Nuremberg, Chair Quality Management and Manufacturing Metrology, Naegelsbachstrasse 25, D-91052 Erlangen, \\ Germany (Albert.Weckenmann@qfm.uni-erlangen.de, $\bowtie$ Teresa.Werner@qfm.uni-erlangen.de, +49 91318526516 )
}

\begin{abstract}
To gather reproducible measurement results, metrologists need a variety of competences. Yet, also other groups of staff in a manufacturing enterprise need competences in metrology in order to assure the appropriate specification of tolerances or sufficient consideration of inspectional requirements in production processes.

Therefore, the strict focus of metrological qualification on staff preparing or performing the actual measurements is insufficient for the efficient assurance of conformity. Additionally, on the one hand a demand-oriented qualification concept is needed to impart required fundamental knowledge on manufacturing metrology according to the specific needs of each user group. On the other hand, appropriate measures of knowledge management have to be applied in order to assure a proper application of the gathered knowledge and enhance mutual understanding for the requirements of other involved user groups.

Thus, as amendment for user-specific measures of formal qualification, a concept has been developed to enable knowledge transfer among different groups and departments in an enterprise. By this holistic approach, the impact of measures of qualification can be increased and high product quality can be achieved as a common aim of all related groups of staff.
\end{abstract}

Keywords: advanced training, Life Long Learning, knowledge management, holistic qualification.

(C) 2010 Polish Academy of Sciences. All rights reserved

\section{Introduction}

The common aim of all activities in manufacturing metrology is the gathering of reliable information about the manufactured products. This information is used to control the implemented processes and to assure that only those workpieces that fulfil the specified requirements are handed on to further steps of production or are delivered to the customers. Regarding the tasks of the metrologist, competence and diligence of the person planning, preparing and executing the measurement may have a significant influence on the gathered result [1] and thus directly on the quality of delivered products. Any errors in the performance of a metrologist's task may cause a biased measuring result without being noticed. Following, based on this wrong information, erroneous decisions will be made. Thus, it is an indispensable precondition for reliable measurement results, that on the one hand the metrologist is capable to perform his tasks and on the other hand also accidental influences on the measurement are reduced as far as possible. Therefore, over the last years a variety of training offers for the impartment of required fundamental skills and knowledge and diverse tools to support the correct execution of a measurement task have been developed (e.g. [2-8] and many others), amending courses by manufacturers of measurement devices which usually focus on handling, programming and maintaining the actual machine.

Yet, the performance of the measurement itself can not be seen as an isolated task. Quite the contrary, the measurement results themselves are worthless, if they are not interpreted correctly or if the measured features do not describe the intended properties of the object. 
Unfortunately, quality inspection is rarely considered as a regular step in the manufacturing process chain, but rather as a merely supportive function. This underestimation of the influence of metrology on the quality of the final product is likely to result in an insufficient recognition of metrological concerns during the development of products and the planning of manufacturing processes, but also in an insufficient allocation of funds for required investment or staff. Finally, this disregard will result in disadvantages for the enterprise. Thus, it is necessary to improve the mutual understanding between different departments in order to enable an execution of specific tasks under consideration of holistic requirements.

Employees in manufacturing metrology or quality inspection have to realize their function as an interfacial area of work and have to keep in close communication with connected departments of the enterprise. In many companies, metrologists are - although often unwillingly - already fulfilling this function, especially if problems occur. But for efficient cooperation, all involved groups need sufficient knowledge about each others' tasks to mutually understand existing concerns.

Therefore, regarding training offers in metrology, the focus has to be opened up from the correct performance of measurement tasks to metrology-related functions in connected professional areas. For this, on the one hand adequate training concepts have to be developed to impart required competences according to the specific demands of different target groups in an industrial enterprise, on the other hand, facilities for knowledge management have to be implemented in order to constantly enhance communication and to assure the actual implementation of abstractly imparted knowledge. Thus, a holistic qualification concept has to be developed, including individual and cooperative learning.

\section{Analysis of group-specific need of competences in metrology}

For an analysis of the needed competences, it has to be regarded which activities are performed by specific user groups in an industrial enterprise and which relation to manufacturing metrology exists. It is necessary to identify existing groups of users considering functional aspects. As each enterprise is organized in a singular way, there will be differences regarding the exact distribution of tasks among the user groups. Yet, it is possible to divide the employees into generic user groups mirroring typical contents of work. Based on this functional categorization, the concept can be developed.

\subsection{Structure of user groups in industrial enterprises}

The analysis of user groups is conducted based on the construct of Porter's value chain (Fig. 1) [9]. In the value chain, strategically important, independent and consecutive activities in an enterprise are visualized. Primary activities contain a direct use for the customer, whereas support activities provide necessary basics for the execution of primary activities. The process results in the manufactured product, providing an economical benefit for the company.

Originally, the construct of the value chain is intended to enable the identification of potentials for economical optimization. The profitability of each of the contained activities may be assessed by comparison with a benchmark partner, e.g. the reference market leader. Thus, the activities are classified in a way that enables a high comparability and transferability between individual enterprises and can be used as a base for the systemoriented analysis of required competences. 


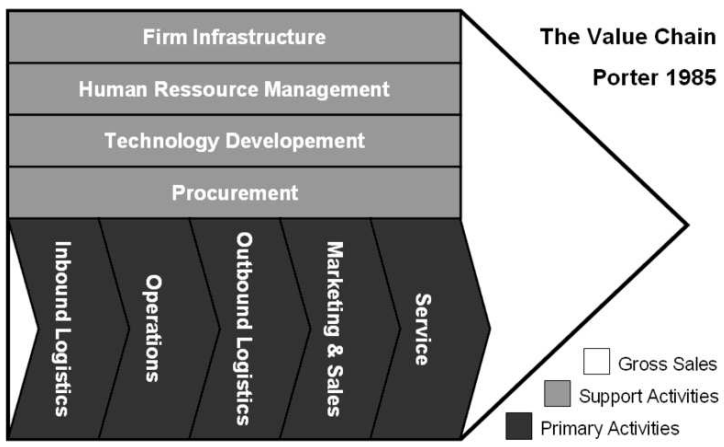

Fig. 1. Porter's model of the value chain [9].

\subsection{Group specific need of competences in metrology}

The first primary activity, inbound logistics, contains the receiving of goods. To assure a sufficient quality of the purchased materials, adequate inspection is necessary. Thus, competences for the planning, execution and interpretation of acceptance inspections for all relevant measurands are necessary. It can be differed by a hierarchical level between the mere execution of a fixed inspection process and the definition of such processes. Also, competences in analyzing measurement results and strategies are necessary in order to identify underlying reasons for differing results between own measurements and supplier documentation.

Operations, the second primary activity, cover the various processes of transforming the input material to output products. Here, information about the quality of manufactured products and the underlying processes are necessary. Thus, competences for initial sample inspection and in-process quality control are necessary, containing planning, execution and interpretation of adept measurements. Especially, knowledge about the reasonable inclusion of quality control in the process is necessary. Here too, hierarchical levels can be differed considering the complexity and amount of the executed tasks.

Outbound logistics is due to deliver the manufactured products to customers. Here, final clearance has to be given for the products. Thus, competences are necessary to prepare and perform the measurement and compare results with the customer, if any differences occur.

Marketing and sales is oriented toward attracting customers for the products. Employees here do not need metrological skills but should know about the quality politics of their enterprise.

The last step of primary activities is service, covering all activities to conserve or augment the value of the product for the customer. Metrological competences are on the one hand necessary to inspect broken parts in order to enable a feedback for the improvement of production processes. On the other hand given measurement results of final clearance by the own company or acceptance inspection by the customer have to be compared and interpreted.

Regarding support activities, in technology development metrological competences are needed to enable inspection-oriented dimensioning during development and construction of new products. For this, fundamental knowledge about different methods of inspection as well as specific knowledge about minimum tolerances to be inspected reliably in the company are required.

Employees in human resource management, procurement and company infrastructure do not need special competences about metrology. Yet, it is very important to assure the appreciation of impact on the company's success gathered by quality control and metrology. Otherwise, strategic decisions regarding infrastructure, investments, employing of qualified 
workers and purchase of required measuring devices will not sufficiently consider the demands of metrology as it is only seen as a factor of cost.

Summarizing, four main groups of employees may be differed regarding their concern with metrological subjects (Fig. 2):

- Metrologists or quality supervisors who actively plan or execute measurement tasks on incoming, produced, outgoing or reclaimed products. This group additionally can be subdivided by the complexity or specialization of executed tasks.

- Contact persons in inbound or outbound logistics or service who do not actively perform measurements but have to be able to interpret measurement results and identify possible reasons for differing results between customer and supplier.

- Constructing and process-planning engineers in operations or technology development who have to know about the requirements of product inspection, their impact on product and process design and the available possibilities.

- Other employees, e.g. in sales, infrastructure or human resource management, who do not need specific metrological knowledge or skills, but a general idea and according appreciation of the impact that metrological activities of the above-mentioned groups have on the success of the company. This requirement for mutual appreciation between different sections of work also holds true for all other areas of activity in a company. Thus, there is no need for a special metrological training concept but rather for an adept overall philosophy.

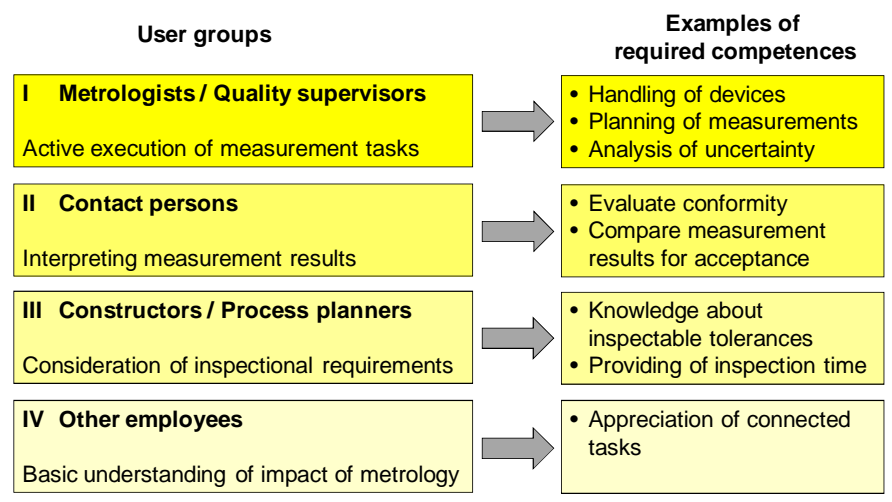

Fig. 2. Typical groups of employees regarding competences in manufacturing metrology.

\subsection{Definition of learning objectives for the user groups}

Out of these identified typical tasks related to metrology, learning objectives for each user group can be defined. Here, primary and secondary objectives have to be regarded (Table 1). Primary objectives focus on factual and procedural competences necessary for the execution of the actual tasks. Therefore, these objectives can be derived directly from the identified tasks. Regarding factual competences, the knowledge about principles and fundamentals required for the specific tasks has to be imparted. Regarding procedural competences, it has to be practiced how to use these abstract information on an actual task at hand.

Secondary objectives focus on general, social and methodical competences that are not specifically required for a certain task, but enable an effective performance within the existing constraints of work. Social competences include the ability to use knowledge in the interaction with other employees and to be able to consider demands of the whole group or other superordinated ideas, e.g. the welfare of the company, in addition to own individual goals. 
Methodical competences contain the ability to link knowledge with new information and thus adapt own actions to new situations and also create new knowledge.

Table 1. Examples of user-group specific learning objectives for different categories.

\begin{tabular}{|c|c|c|c|c|}
\hline & & Exemplary learning & ectives & \\
\hline User groups & Factural & Procedural & Methodical & Social \\
\hline $\begin{array}{l}\text { I Metrologists / } \\
\text { Quality supervisors }\end{array}$ & $\begin{array}{l}\text { Knowledge about } \\
\text { measuring devices }\end{array}$ & $\begin{array}{l}\text { Ability to handle and } \\
\text { program measuring } \\
\text { machine }\end{array}$ & \multirow{4}{*}{$\begin{array}{l}\text { Diligent, } \\
\text { self- } \\
\text { controlled } \\
\text { working }\end{array}$} & \multirow{4}{*}{$\begin{array}{l}\text { Consider } \\
\text { connections } \\
\text { to other } \\
\text { working } \\
\text { steps }\end{array}$} \\
\hline II Contact persons & $\begin{array}{l}\text { Knowledge about } \\
\text { meaning of } \\
\text { measuring } \\
\text { uncertainty }\end{array}$ & $\begin{array}{l}\text { Ability to assess } \\
\text { conformity of a part } \\
\text { considering } \\
\text { uncertainty }\end{array}$ & & \\
\hline $\begin{array}{l}\text { III Constructors / } \\
\text { Process planners }\end{array}$ & $\begin{array}{l}\text { Knowledge about } \\
\text { available } \\
\text { measurement } \\
\text { devices }\end{array}$ & $\begin{array}{l}\text { Ability to transfer } \\
\text { abstract knowledge to } \\
\text { construction }\end{array}$ & & \\
\hline IV Other employees & --- & --- & & \\
\hline
\end{tabular}

Basically, it is considered that social and methodical competences have been sufficiently developed during primary education. Yet, the analysis of tasks with metrological concern for the various areas of activities shows that, due to the demanded cooperation, competences in social interaction and methodical working have an extremely strong influence on the successful and efficient execution of the tasks at hand. Therefore, further consideration of these secondary objectives can be regarded as vital for the impact of the intended group-specific training on the performance of the participants.

Thus, the mere impartment of knowledge is not sufficient, but amending measures to enhance cooperation and knowledge management between different departments are required.

\section{Conceptualization of training offer}

For the definition of a training concept, a teaching-learning methodology has to be defined according to the requirements and preferences of the intended target group. Also, the content has to be defined which has to be imparted to achieve the specified learning objectives. For this, it is necessary to know the typical qualification profile of the participants in order to determine the preknowledge to be considered. The employees of the mentioned groups typically differ widely regarding basic vocational qualification and professional experience. Thus, it is not recommendable to define the expected state of existing metrological competences based on an analysis of contents in basic vocational education. This holds true also for the constraints on teaching-learning methodology. Therefore, it is necessary to conduct a user-needs analysis to describe requirements on the method to be implemented as well as on the detail of knowledge to be imparted and the starting point. Out of the results gathered there, components adapted to the needs of each user group can be developed, intended to achieve the learning objectives regarding factual and procedural competences [10].

Regarding the intended knowledge management, the according component has to fit all groups as it has to include members of all related departments. Also, demand for time or resources should be as low as possible to enable an inclusion in working conditions rather than an outstanding 
action which is not likely to create a sustainable learning effect. Therefore, cooperative learning in project groups that work together on an actual problem out of the own enterprise is recommended, implementing the widely known technique of quality circles as an opportunity for learning. The project group should consist of members of all departments relevant for the conduction of metrological analysis on a specific part, that is, quality planning with metrology in any case, amended by product development, process planning, and logistics if appropriate for the chosen actual task. For this method of cooperative learning on a project, there are no requirements on the ability to use any kind of special learning methodology, but only everyday abilities are required. Also, the amount of necessary time is quite low and additionally is immediately rewarded.

For the problem to be solved, a workpiece should be chosen which causes difficulties during its processing. Optimally, it can be considered as a special representative for a group of similar workpieces with comparable problems. Then, the project group is bound to use their specific competences and knowledge to find an acceptable solution for the processing of this workpiece, satisfying the needs of all involved groups. For example, a workpiece can be analyzed that is developed and manufactured in the enterprise and then assembled with other self-produced parts to a subgroup or the final product. Here, typical problems are difficulties in inspecting the defined specifications with acceptable accuracy given the available equipment and the time reserved for inspection in the manufacturing process which may result in erroneous parts not usable for assembling, as reported by metrologists in different enterprises. Specific concerns can be the relation of the specification to the required functions, the allowed size of deviations or other aspects. To find an acceptable solution for this task, requirements and concerns of product development, quality inspection, process planning, production of the parts and assembly with other parts have to be known. Therefore, from each of these departments one person should join the project group. It is recommendable, that - at least at the beginning of this cooperative process - no employee has to reanalyze his own work, in order to avoid the need to maintain own integrity by defending taken decisions. Later on in the learning process, the reanalyzing of own work will be more helpful, if a better understanding for the concerns of other departments' needs results in the ability to critically reflect own decisions.

This project work should be conducted interrelated with the impartment of theoretical knowledge (Fig. 3). Thus, phases of group specific learning have to change with phases of cooperative learning. For the conduction of the project work, a specified time has to be reserved in order to enable concentrated working, e.g. one afternoon in a month. The chosen tasks have to be solvable in the given time frame. Thus, it is preferable to chose small tasks as examples which enable the success of the project group. During the common work, the mutual understanding will be sustainably increased.

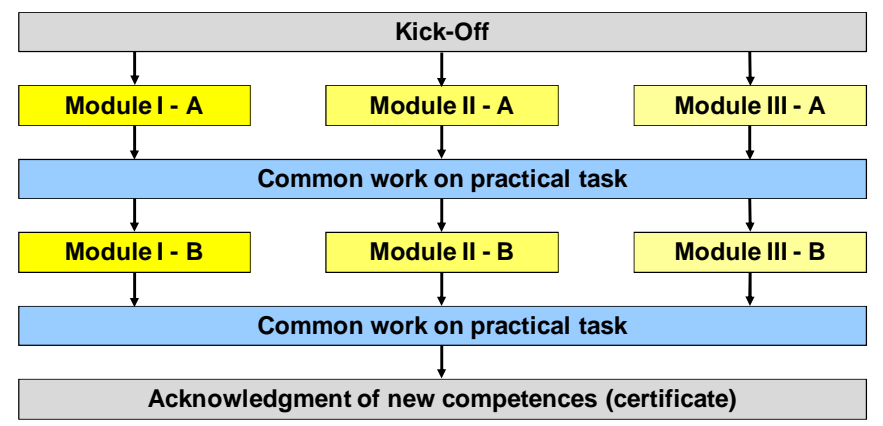

Fig. 3. Concept of a user-group specific training enhancing knowledge exchange. 


\section{Constraints for the effectiveness of Cooperative learning for knowledge management}

For the successful implementation of any method of knowledge management, a triangle of areas in the enterprise has to be regarded: Technique, organisation and human being [11]. Even a good technique or method is of no use if the organisational constraints do not allow for a proper use and the individual employee is not able or not motivated to participate in the process of knowledge management.

If the overall situation does not enable self-guided working and a comprehensive considering of the advice and new ideas taken out of the cooperative learning circles, but only a strict processing of instructions, a process of learning or knowledge transfer will not be possible. If all further actions are based on binding, predefined rules, at least the activities are transparent and reproducible. Yet, it is usually not possible to define simple instructions for complex problems in an adequate way. More likely, in some cases the unconsidered relying on these instructions will lead to erroneous performances, if they are not applicable or not optimized to a specific situation out of given constraints.

Therefore, to sustainably achieve high standards in the performance of complex processes it is indispensable to enable a sufficient degree of self-guidance for all involved employees. Complementarily, it is necessary to promote a feeling of responsibility for their specific area of duty and to show the importance of knowledge management and sharing of experience for the overall success of a specific process as well as on a long term for the whole company, including all employees.

Regarding the involved employees, proper use of the project work or any facility for knowledge management or continuous learning can only be expected if the employee is adequately motivated. Otherwise, these methods will not be accepted. For this, it is necessary to provide some basic information:

- Organisation of the method. The organisation of the project groups and their connection to the overall learning process should be made clear.

- Benefit of knowledge management for the company and the employee himself. An efficient sharing of knowledge can only be implemented if all concerned persons are motivated to participate adequately. Therefore, the use of knowledge sharing for the company, but especially also for the individual employee as opposed to the use of rare competences as a valuable source of power or a sort of security guarantee regarding dismissal, has to be understood.

- Benefit of better results. In a long term, an active participation in a process of constant improvement and supportive cooperation can only be achieved if a common aim is aspired. In metrology, that would be the ideal situation of precise and unbiased measurement results understandable by all concerned persons and reproducible with adequate accuracy. Thus, the employee will be motivated not only to oblige to existing rules, but to contribute actively to a continuous development and to sustainably improve his own performance.

In order to impart the necessary competences and understanding, a proper introduction to the implemented method will have to take place as part of the training concept. Also, information about the policy and vision of the company as a learning community is necessary. Finally, a general involvement in the process of Life Long Learning is indispensable in order to achieve a sustainable motivation and an adequate identification with the aims of an assignment.

\section{Conclusions and outlook}

The reliability of measurement results depends not only on the performance of the actual measurement, but also on its embedding in overall manufacturing processes. There are many 
connections with other departments regarding the specification of properties to be measured as well as the interpretation and handling of measurement results and the definition of constraints for the measurement itself. Therefore, qualification for metrology also has to consider other user groups besides the metrologists themselves.

By a structured analysis based on Porter's value chain three typical user groups in industrial companies have been identified with specific need for advanced training on metrological concerns. This analysis provides a base for the development and implementation of demandoriented training concepts for these user groups. Learning objectives have been derived from the general systemic analysis of required competences. Based on the results of a user-needs analysis, an according training concept has been developed. To achieve a sustainable learning effect and enable the imparting of social and methodical competences required for the efficient performance of metrology-related tasks, the impartment of abstract knowledge has to be combined with according measures of knowledge management. For this element, the method of cooperative learning in project groups has been proposed.

By implementing such a holistic qualification concept sensitive to the needs of different user groups in an enterprise, an educational offer can be provided to enable the correct handling of measurement results in industrial application, concerning not only the execution of measurements, but also the interpretation of measurement results and the related communication as well as the basic consideration of inspectional requirements. Thus, the reliability of measurement results as a basis for the quality of manufactured products can be increased.

\section{Acknowledgments}

The authors would like to thank their student Larissa Vogel whose results on relation of typical groups in an industrial enterprise found in a study project contributed to the underlying research.

\section{References}

[1] T. Pfeifer: Production Metrology. Oldenbourg, München, 2002.

[2] A.R. de Sousa, R. Gonzáles, S. Conejero: "FORMA3D - An educational program for the qualification of technical person involved with coordinate metrology in Brazil”. Proc. of IMEKO XVIII World Congress and IV Brazilian Congress of Metrology, Rio de Janeiro, Brazil, Sept. 2006, pp. 10.

[3] A. Weckenmann, L. Blunt, S. Beetz S: European Training in Coordinate Metrology - Components of a training concept for Coordinate Metrology: Situation - Curriculum - Methodology - Training system Experiences. “impuls”, vol. 20, Oct. 2005.

[4] Weckenmann, T. Werner: "Training on Basics for Industrial Metrology by Integration of Work and Learning in the Project Mess-iN". Proc. of IMEKO XVIII World Congress and IV Brazilian Congress of Metrology, Rio de Janeiro, Brazil, Sept. 2006, pp. 7.

[5] F. Annemüller, U. Nehse, D. Ernst: "Dynamic vision training module for i-Learning in industrial applications". Proc. of Joint International IMEKO TC1 + TC7 Symposium, Ilmenau, Germany, Sept. 2005, pp. 111-114.

[6] A. Weckenmann, S. Beetz: "Computer-based integrated assistance for coordinate measurements". Proc. of XVII IMEKO World Congress, Dubrovnik, Croatia, June 2003, pp. 118.

[7] S. Echeverría-Villagómez, M. Flores-Campos, R. Pantoja-Lesso, N. Rodríguez-Damián, B. ValganónArgueta: "Human resource and knowledge management system for competences in metrology using information technologies". Proc. of IMEKO XVIII World Congress and IV Brazilian Congress of Metrology, Rio de Janeiro, Brazil, Sept. 2006, pp. 11.

[8] H.K. Mischo, T. Pfeifer, F. Bitte: "Model-based optimization of interferometers for testing aspherical surfaces". Proc. of SPIE 45th Annual Meeting, San Diego, USA, 2000, pp. 497-510. 
[9] M. Porter: Competitive Advantage: Creating and Sustaining Superior Performance. Free Press, New York, 1985.

[10]A. Weckenmann, T. Werner: "Development of user group specific training concepts for metrology in industrial application". Proc. of XIX IMEKO World Congress, Lisbon, Portugal, Sept. 2009, pp. 4-9, http://www.imeko2009.it.pt/Papers/FP_422.pdf.

[11]H.J. Bullinger, K. Wörner, J. Prieto: Wissensmanagement - Modelle und Strategien für die Praxis. H.D. Bürgel (Ed.): Wissensmanagement - Schritte zum intelligenten Unternehmen. Springer, Berlin, 1998. 